\title{
Isothermal Transport (Core-Flow Type) of Heavy and Ultraviscous Oil in Curved Pipes: A Transient Study by CFD
}

\author{
Bruno Ferreira Silva1, Hortência Luma Fernandes Magalhães ${ }^{2}$, Ricardo Soares Gomez ${ }^{1}$, \\ Endyara de Morais Cabral ${ }^{1}$, Francisco Alves Batista ${ }^{3}$, Adriana Barbosa da Costa Pereira ${ }^{2}$, \\ Wanderson Magno Paiva Barbosa de Lima ${ }^{1}$, Antonio Gilson Barbosa de Lima ${ }^{1}$
}

\author{
${ }^{1}$ Department of Mechanical Engineering, Federal University of Campina Grande, Campina Grande-PB, Brazil \\ ${ }^{2}$ Department of Chemical Engineering, Federal University of Campina Grande, Campina Grande-PB, Brazil \\ ${ }^{3}$ Department of Physics, State University of Paraiba, Campina Grande-PB, Brazil \\ Email: brunofs_engenharia@hotmail.com, ricardosoaresgomez@gmail.com, antonio.gilson@ufcg.edu.br, \\ endyara.engpetro@gmail.com,wan_magno@hotmail.com, hortencia.luma@gmail.com, adrianabarbosaabc@yahoo.com.br, \\ chicoalves13@hotmail.com
}

How to cite this paper: Silva, B.F., Magalhães, H.L.F., Gomez, R.S., de Morais Cabral, E., Batista, F.A., da Costa Pereira, A.B., de Lima, W.M.P.B. and de Lima, A.G.B. (2020) Isothermal Transport (Core-Flow Type) of Heavy and Ultraviscous Oil in Curved Pipes: A Transient Study by CFD. Open Journal of Fluid Dynamics, 10, 122-134. https://doi.org/10.4236/ojfd.2020.102008

Received: April 9, 2020

Accepted: May 29, 2020

Published: June 2, 2020

\section{Copyright $\odot 2020$ by author(s) and} Scientific Research Publishing Inc. This work is licensed under the Creative Commons Attribution International License (CC BY 4.0).

http://creativecommons.org/licenses/by/4.0/

(c) (i) Open Access

\begin{abstract}
In the scenery of the oil industry, the remaining resources associated with light oils have an increasingly smaller share in the natural energy resources available to man, and in return the importance of resources associated with heavy oils has increased significantly. One of the drawbacks of this type of oil is associated with its low mobility due to the high viscosity in reservoir conditions, making the transport in pipelines very difficult, especially through pumping methods that require high powers. Thus, the development of new techniques and optimization of some existing technologies, aiming at the commercial use of heavy oil accumulations plays an important role. A viable technique that has been used is the core annular flow, in which small amounts of water are injected close to the pipe wall, lubricating the oil core, reducing friction and decreasing the pressure drop during the flow. In this sense, this work aims to perform, numerically, an energetic and hydrodynamic analysis of a heavy oil-water two-phase flow, using the core-flow technique, in curved pipes, in the Ansys CFX software. Results of the velocity, pressure, and volume fraction distribution of the involved phases are presented and analyzed. It was observed that the proposed mathematical model was able to accurately represent the analyzed phenomena and that a reduction factor in the pressure drop of 28.4 was obtained as compared to the heavy oil single-phase flow.
\end{abstract}

\section{Keywords}

Core-Flow, Simulation, Two-Phase Flow, CFD, Ansys CFX 


\section{Introduction}

In the world oil production scenario, light oils, also called conventional oils, have dominated the market throughout history. These oils are technically easier to produce, have a lower production cost, higher performance after being refined, in addition to providing high-value products [1]. However, in recent decades its accumulations have been reduced gradually. Thus, there is an interest in potential heavy oil reserves, estimated by the IEA (International Energy Agency) at around 6 trillion barrels around the world [2].

Heavy oils are composed of high molecular weight hydrocarbons, consequently, they have a high relative density, related to the presence of unwanted product contents such as asphaltenes, metallic components (nickel and vanadium) and sulfur. Furthermore, they are characterized by having a low API degree, between 10 and 20, and high viscosity ranging from $100 \mathrm{cP}(0.1 \mathrm{~Pa} \cdot \mathrm{s})$ to $10,000 \mathrm{cP}$ (10 Pa.s). The production of this type of oil is, on average, twice as expensive in terms of production cost and energy consumption. This fact is related to low mobility due to its high viscosity in reservoir conditions, along with the presence of unwanted components already mentioned, making it more difficult to produce, transport and refine these oils.

In Brazil, the Campos Basin is the location that contains the largest amount of heavy oil in deep waters, being responsible for approximately $90 \%$ of the oil production in the country [3]. Producing heavy oil in deep waters and transporting it in pipelines are expensive and highly complex tasks. The main problems are related to guarantee the flow of oil in severe conditions, subject to the hydrate formation and the paraffin deposition on the inner walls of the pipeline, and ensure the proper pressure drop in the flow. In some cases, problems such as the paraffin deposition can cause an increase in the pumping power requirement, decreasing in the volumetric flow rate, and even causing the complete blockage of the pipeline.

Core Annular Flow (CAF) can be defined as an alternative technique for transporting heavy oils. This technique uses parietal lubrication, that is, the annular flow of water in the pipe to carry the heavy oil in the center, thus, reducing friction effects [4], and the lowest amount of energy required for pumping [5]. Due to its high potential, several researchers have given the great interest in developing works related to this technique [6]-[16]. Unfortunately, several works are related to horizontal and vertical pipes, and few researches are focused on non-conventional geometries [17] [18] [19] [20] [21].

Sarmadi et al. developed a methodology for transporting heavy oil using an annular flow with three layers. The third layer, next to the wall, is a lubricating layer. These authors verified that the addition of the extra layer ensures the stability of the transport, allowing a stable annular flow. Furthermore, they authors verified that the method produces a significant reduction in pressure drop.

Ameri et al. [22] studied the core-flow system in a vertical pipe in a configuration with onlulated nucleus. These authors found that the ideal proportion for 
water and oil input ranged from 0.07 to 0.5 depending on the surface velocity of the oil transported. Furthermore, in the research was verified that a higher oil flowrate requires smaller amounts of water to reach the minimum friction pressure gradient.

Strazza et al. [23] carried out a trial study of resuming a core-flow system starting from a stratified flow. The authors comment about the importance of the water injection velocity in removing the oil that is trapped to lipophilic wall, and to keep the stable oil core.

During the Core Annular Flow, numerous difficulties related to the transportation of heavy oils are encountered. Given the importance of the physical problem under discussion, there is a need for further studies on the development and optimization of existing techniques, thus allowing the commercial use of these reserves from a technical and economic point of view. Therefore, in complement of this topic, this work aims to perform, numerically, an energetic and hydrodynamic analysis of a heavy oil-water two-phase flow, using the core-flow technique, in non-conventional ducts (curved pipes).

\section{Methodology}

\subsection{The Physical Problem and the Geometry}

The physical problem to be studied herein consists of the two-phase flow (core-flow type) of heavy oil in a curved pipe (Figure 1). For this propose was used the computational fluid dynamics (Ansys CFX ${ }^{\circledR}$ commercial software).

In the present work, a structured three-dimensional mesh representing the study domain was generated in the ICEM CFD module of the ANSYS CFX 12.0 software. This mesh was created using a set of points, curves, surfaces, and solids describing its shape (curved pipe) and dimensions (diameter and length). The

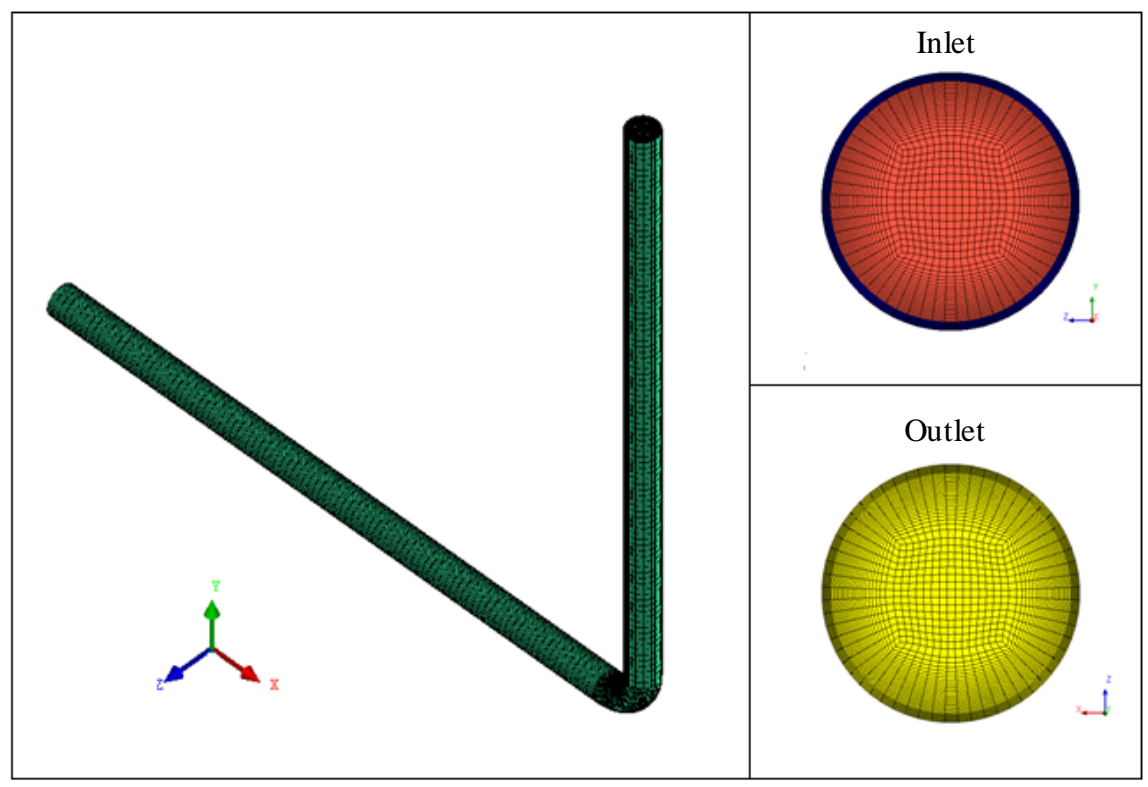

Figure 1. Mesh used in the simulations. 
modeling of the physical problem with appropriated boundary conditions were specified in the Ansys CFX ${ }^{\circledR}$.

Figure 1 shows the numerical mesh from the curved pipe with a total length of $12 \mathrm{~m}$ and a curvature radius equal to $0.2 \mathrm{~m}$. In the oil inlet regions, an internal diameter $\left(D_{i}=0.14 \mathrm{~m}\right)$ and the external diameter of the pipe $\left(D_{e}=0.15 \mathrm{~m}\right)$ were adopted, where the annular region $\left(D_{e}-D_{i}\right)$ refers to the water inlet. This arrangement causes water to flow in the annular region, lubricating the oil core and thus reducing friction between the oil and the pipe wall. This mesh was obtained after the grid and time refinements.

\subsection{Mathematical Modeling}

The heavy oil-water two-phase flow in curved pipes is governed by general conservation laws, as follows:

1) Mass Conservation Equation:

$$
\frac{\partial}{\partial t}\left(f_{\alpha} \rho_{\alpha}\right)+\nabla\left(f_{\alpha} \rho_{\alpha} \boldsymbol{U}_{\alpha}\right)=S_{M S \alpha}+\sum_{\beta=1}^{N_{p}} \Gamma_{\alpha \beta}
$$

where the sub-indices $\alpha$ and $\beta$ correspond to the involved phases; $f$ is the volume fraction, $\rho$ is the density, $\boldsymbol{U}$ is the velocity vector; $S_{M S}$ is the mass source term and $\Gamma_{\alpha \beta}$ is the mass transfer term between the fluid phases.

2) Momentum Equation:

$$
\begin{aligned}
& \frac{\partial}{\partial t}\left(f_{\alpha} \rho_{\alpha} \boldsymbol{U}_{\alpha}\right)+\nabla \cdot\left[f_{\alpha}\left(\rho_{\alpha} \boldsymbol{U}_{\alpha} \otimes \boldsymbol{U}_{\alpha}\right)\right] \\
& =-f_{\alpha} \nabla p_{\alpha}+\nabla \cdot\left\{f_{\alpha} \mu_{\alpha}\left[\nabla \boldsymbol{U}_{\alpha}+\left(\nabla \boldsymbol{U}_{\alpha}\right)^{\mathrm{T}}\right]\right\}+\sum_{\beta=1}^{N_{p}}\left(\Gamma_{\alpha \beta}^{+} \boldsymbol{U}_{\beta}-\Gamma_{\beta \alpha}^{+} \boldsymbol{U}_{\alpha}\right)+\boldsymbol{S}_{M \alpha}+\boldsymbol{M}_{\alpha}
\end{aligned}
$$

where $\mu$ is the dynamic viscosity, $p$ is the pressure, $\otimes$ is tensor product, $S_{M}$ represents the term of the external forces acting on the system per volume unit. In the term referring to the momentum transfer induced by the interfacial mass transfer (the third term on the right side of the equation), $\Gamma_{\alpha \beta}^{+}$corresponds to the mass flow rate per unit volume of the phase $\beta$ to phase $\alpha$ and vice-versa.

The tensor product of two vector is given by:

$$
\boldsymbol{U} \otimes \boldsymbol{U}=\left(\begin{array}{ccc}
U_{x} U_{x} & U_{x} U_{y} & U_{x} U_{z} \\
U_{y} U_{x} & U_{y} U_{y} & U_{y} U_{z} \\
U_{z} U_{x} & U_{z} U_{y} & U_{z} U_{z}
\end{array}\right)
$$

and the term $\nabla \cdot(f \rho \boldsymbol{U} \otimes \boldsymbol{U})$ can be obtain by:

$$
\nabla \cdot(f \rho \boldsymbol{U} \otimes \boldsymbol{U})=\left(\begin{array}{lll}
\frac{\partial}{\partial x}\left(f \rho U_{x} U_{x}\right) & \frac{\partial}{\partial y}\left(f \rho U_{x} U_{y}\right) & \frac{\partial}{\partial z}\left(f \rho U_{x} U_{z}\right) \\
\frac{\partial}{\partial x}\left(f \rho U_{y} U_{x}\right) & \frac{\partial}{\partial y}\left(f \rho U_{y} U_{y}\right) & \frac{\partial}{\partial z}\left(f \rho U_{y} U_{z}\right) \\
\frac{\partial}{\partial x}\left(f \rho U_{z} U_{x}\right) & \frac{\partial}{\partial y}\left(f \rho U_{z} U_{y}\right) & \frac{\partial}{\partial z}\left(f \rho U_{z} U_{z}\right)
\end{array}\right)
$$

In Equation (2), $\boldsymbol{M}$ describes the interfacial force per unit volume over the 
phase $\alpha$ due to the interaction with the phase $\beta$. This parameter represents the sum of several forces, such as wall lubrification force, lift force, interfacial drag force, virtual mass force, turbulent dispersion force and solids pressure force. In the work, we use the mixing model at the interface between the phases. In this case, only the interfacial drag force is considered, being given by:

$$
\boldsymbol{M}_{\alpha}=C_{D} \rho_{\alpha \beta} A_{\alpha \beta}\left|\boldsymbol{U}_{\beta}-\boldsymbol{U}_{\alpha}\right|\left(\boldsymbol{U}_{\beta}-\boldsymbol{U}_{\alpha}\right)
$$

where $C_{D}=0.44$ is the drag coefficient [24], and $\rho_{\alpha \beta}$ is the density of the fluid mixture, given as follows:

$$
\rho_{\alpha \beta}=f_{\alpha} \rho_{\alpha}+f_{\beta} \rho_{\beta}
$$

The viscosity of the fluid mixture is given by:

$$
\mu_{\alpha \beta}=f_{\alpha} \mu_{\alpha}+f_{\beta} \mu_{\beta}
$$

The interfacial area density per volume unit, $A_{\alpha \beta}$, defines the treatment model for interfacial transfer (particle, mixture and free surface models). In this research we use the following equation:

$$
A_{\alpha \beta}=\left|\Delta f_{\alpha}\right|
$$

\section{3) Turbulence equations:}

The $k-\mathcal{E}$ turbulence model was used to describe the flow of the water phase. This is a turbulent viscosity model where Reynolds tensors are assumed to be proportional to the mean velocity gradients, with the constant of proportionality being characterized by the turbulent viscosity (idealization known as Boussinesq's hypothesis).

The characteristic of this type of model is that two transport equations modeled separately are solved for the turbulent length and the time scales or any two combinations linearly independent of them. The variable $k$ represent the transport equation for the turbulent kinetic energy, and $\varepsilon$ represent the turbulent kinetic energy dissipation rate, as follows:

$$
\begin{gathered}
\frac{\partial}{\partial t}\left(\rho_{\alpha} f_{\alpha} k_{\alpha}\right)+\nabla \cdot\left\{f_{\alpha}\left[\rho_{\alpha} \boldsymbol{U}_{\alpha} k_{\alpha}-\left(\mu+\frac{\mu_{\mathrm{t} \alpha}}{\sigma_{k}}\right) \nabla k_{\alpha}\right]\right\}=f_{\alpha}\left(G_{\alpha}-\rho_{\alpha} \varepsilon_{\alpha}\right) \\
\frac{\partial}{\partial t}\left(\rho_{\alpha} f_{\alpha} \varepsilon_{\alpha}\right)+\nabla \cdot\left\{f_{\alpha} \rho_{\alpha} \boldsymbol{U}_{\alpha} \varepsilon_{\alpha}-\left(\mu+\frac{\mu_{\mathrm{t} \alpha}}{\sigma_{\varepsilon}}\right) \nabla \varepsilon_{\alpha}\right\}=f_{\alpha} \frac{\varepsilon_{\alpha}}{k_{\alpha}}\left(C_{1} G_{\alpha}-C_{2} \rho_{\alpha} \varepsilon_{\alpha}\right)
\end{gathered}
$$

where $G_{\alpha}$ is the generation of turbulent kinetic energy within phase $\alpha, C_{1}$ and $C_{2}$ are empirical constants. The dissipation rate of turbulent kinetic energy and the turbulent kinetic energy of phase $\alpha$, are, respectively, defined by:

$$
\begin{gathered}
\varepsilon_{\alpha}=\frac{c_{\mu} q_{\alpha}^{3}}{l_{\alpha}} \\
k_{\alpha}=\frac{q_{\alpha}^{2}}{2}
\end{gathered}
$$

where $l_{\alpha}$ is the length of the spatial scale, $q_{\alpha}$ is the velocity scale and, $c_{\mu}$ is an empirical constant, being as follows: 


$$
c_{\mu}=4 c_{\alpha}^{2}
$$

where $c_{\alpha}$ is an empirical constant and $\mu_{t \alpha}$ corresponds to turbulent viscosity, defined by:

$$
\mu_{t \alpha}=c_{\mu} \rho_{\alpha} \frac{k_{\alpha}^{2}}{\varepsilon_{\alpha}}
$$

The value of the constants used in the Equation (7) and Equation (8) are: $C_{1}=$ 1.44, $C_{2}=1.92, C_{\mu}=0.09, \sigma_{k}=1.0$, and $\sigma_{\varepsilon}=1.3$. These information can be found in the literature.

\subsection{Initial and Boundary Conditions}

As an initial condition, it was considered that the entire pipe was filled with water. The boundary conditions applied to the study domain are as follows:

1) An annular section for the inlet of water:

$$
R_{i}<r<R_{e} \Rightarrow\left\{\begin{array}{l}
\dot{Q}_{w}=4.0779 \mathrm{~kg} / \mathrm{s} \\
f_{w}=1.0 \\
U_{0}^{z}=f_{0}=0
\end{array}\right.
$$

2) An inlet section for oil:

$$
0<r<R_{i} \Rightarrow\left\{\begin{array}{l}
\dot{Q}_{0}=\left(15-1.5 t^{2}\right) \mathrm{kg} / \mathrm{s} \therefore 0 \leq t \leq 10 \mathrm{~s} \\
f_{0}=1.0 \\
U_{w}^{z}=f_{w}=0
\end{array}\right.
$$

where $t$ is the time.

3) At the boundaries of the pipe wall: a roughness value of $4.5 \times 10^{-5} \mathrm{~m}$ and the no-slip condition were considered.

$$
r=\left\{\begin{array}{l}
U_{w}^{r}=U_{w}^{\theta}=U_{w}^{z}=0 \\
U_{0}^{r}=U_{0}^{\theta}=U_{0}^{z}=0
\end{array}\right.
$$

\subsection{Fluid Properties and Numerical Procedures}

The properties of the fluids used in the numerical simulation of the heavy oil-water two-phase flow, using the core-flow technique, are shown in Table 1.

Regarding the numerical simulation of the physical problem, some assumptions were made, which are shown in Table 2.

\section{Results and Discussion}

The numerical simulation was carried out in a transient state with a total process time equal to $t=10 \mathrm{~s}$ and a time-step $\Delta t=0.05 \mathrm{~s}$. As evidenced in the initial and boundary conditions, the water flow rate is constant (iqual to $4 \mathrm{~kg} / \mathrm{s}$ ), while the oil flow rate is a time-dependent function with decreasing behavior (decreasing from 15 to $0 \mathrm{~kg} / \mathrm{s}$ ), as shown in Figure 2. This type of simulation tries to show the behavior of the core-flow when the pumping of oil decreases in the course of the process keeping the water flow rate to be constant. The idea is to approach 
Table 1. Thermophysical properties of the fluids used in the numerical simulation.

\begin{tabular}{|c|c|c|}
\hline Property & Heavy oil & Water \\
\hline Density $\left(\mathrm{kg} / \mathrm{m}^{3}\right)$ & 989 & 997 \\
\hline Dynamic viscosity (Pa.s) & 10 & $8.89 \times 10^{-4}$ \\
\hline Surface tension $(\mathrm{N} / \mathrm{m})$ & & \\
\hline
\end{tabular}

Table 2. Assumptions made to solve the governing equations.

\begin{tabular}{cc}
\hline Properties & Assumptions \\
\hline Classification of fluid flow & $\begin{array}{c}\text { Two-phase flow (oil-water), three-dimensional, transient, } \\
\text { incompressible, isothermal, turbulent (water)/laminar (oil) }\end{array}$ \\
Turbulence model & $k$ - $\varepsilon$ Standard \\
Multiphase model & Non-homogeneous \\
Interfacial transfer model & Mixing model \\
Interfacial force & Drag \\
Pressure interpolation scheme & Trilinear \\
Velocity interpolation scheme & Trilinear \\
Advection scheme & High Resolution
\end{tabular}

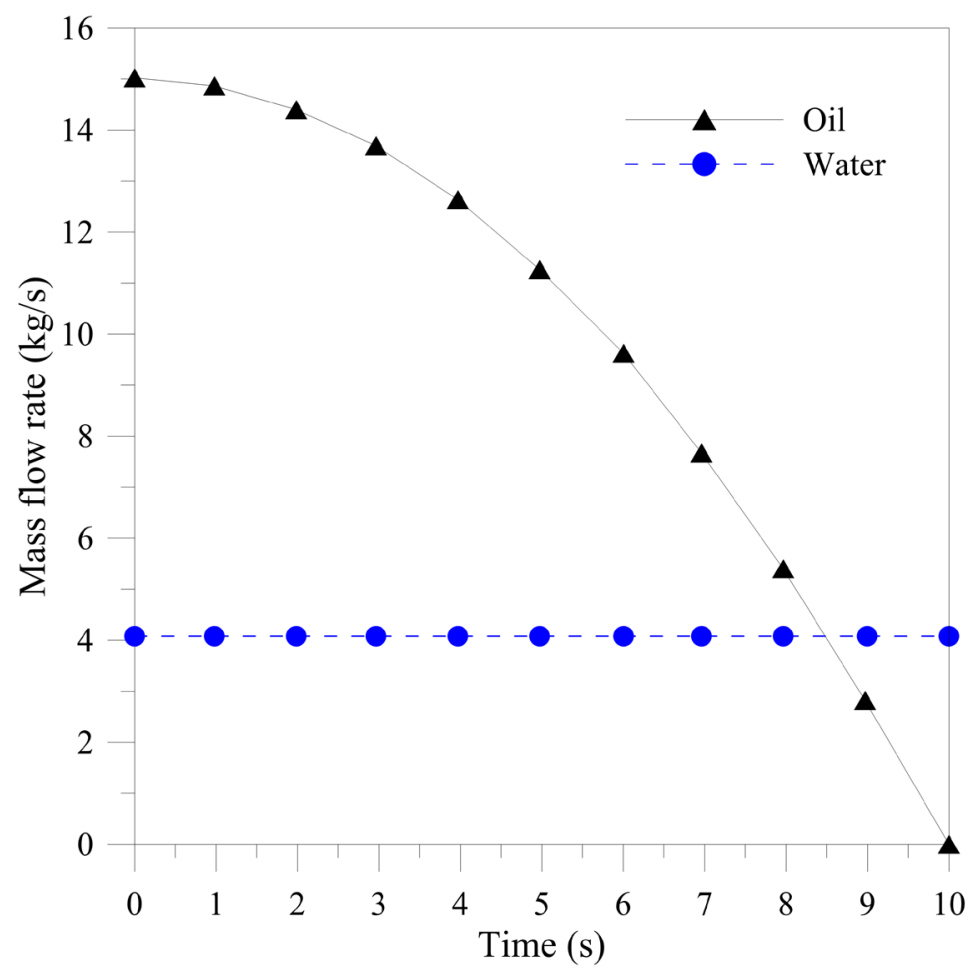

Figure 2. Transient behavior of mass flow rates of oil and water phases.

this physical situation to a real process such as a performance reduction of the oil pump due to a problem in the suction of the pipeline or even a variation in the engine rotation velocity done manually to attend operational requirements. 
Figure 3 illustrates the behavior of the pressure drop and the required power as a function of time. From the analysis of this figure, it is observed that maximum value is obtained and it can be used as a parameter for dimensioning the system. The maximum pressure drop obtained for oil transportation using the core-flow technique was $\Delta P=2879.37 \mathrm{~Pa}$, which corresponds to the maximum power required of $41.14 \mathrm{~W}$. Note that length of the pipe is $12 \mathrm{~m}$ only. The pipe is full filled with water in $t=0 \mathrm{~s}$ and following, the oil and water starts to flow along the pipe, simultaneously.

The pressure field at time $t=3 \mathrm{~s}$ and $6.5 \mathrm{~s}$ are shown in Figure 4. By analyzing the figure, we can see a decrease in fluids flow pressure due to friction along the

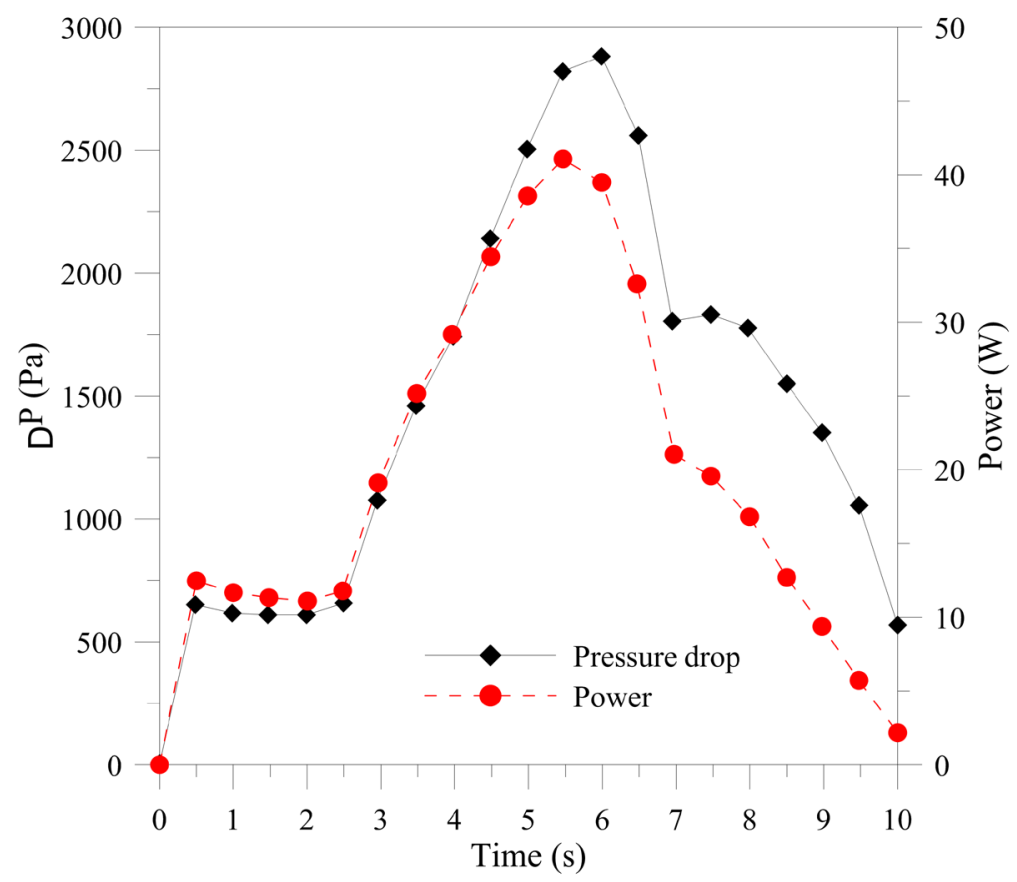

Figure 3. Transient behavior of the pressure drop and pumping power required during $10 \mathrm{~s}$ of process.

Pressure

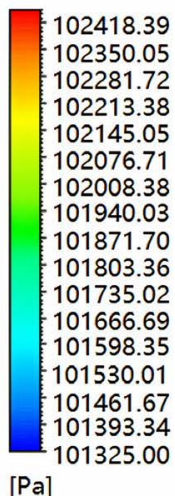

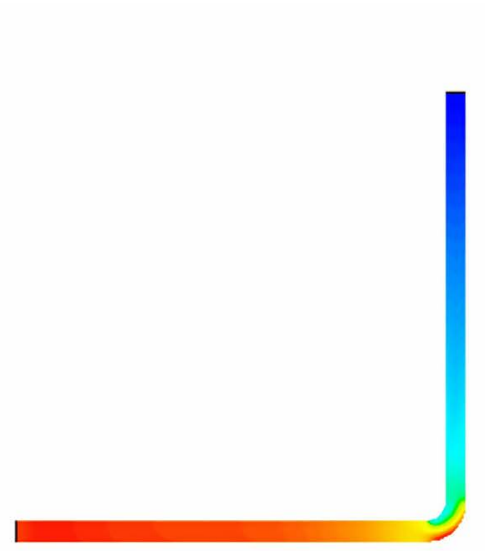

(a) $t=3 \mathrm{~s}$

\section{Pressure}

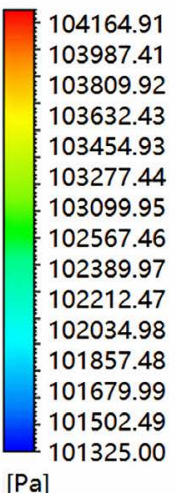

[Pa]

(b) $t=6.5 \mathrm{~s}$

Figure 4. Pressure field along the pipe at different moments. 
pipe wall, especially in the curvature region, as expected for at this geometry type.

In the petroleum industry always is desirable to transport crude oil as possible at fixed pressure drop. Thus, to compare the performance of the core-flow technique plays important role. For heavy oil single-phase flow, the pressure drop achieved was $\Delta P=81780.9 \mathrm{~Pa}$. Therefore, a reduction factor of 28.4, which is the relationship between the pressure drop of the oil single-phase flow and the two-phase flow using the core-flow technique, was verified. There was a reduction in pressure drop equivalent to $96.48 \%$ when using the core-flow technique for transporting heavy oil, thus showing its efficiency in terms of the high-energy gain in the process, that is essential to make the production of heavy oils to be optimized and economically attractive.

Figure 5 and Figure 6 show the volumetric fraction field of the oil along the pipe. Variations in volumetric fraction can be interpreted like a mixture of the involved phases or even formed emulsion. From the analysis of these figures, it can be seen that the oil core remains stable, being lubricated by the water that flows close to the pipe wall in the annular region. However, the oil core is non-concentric,

\section{Oil volumetric fraction}

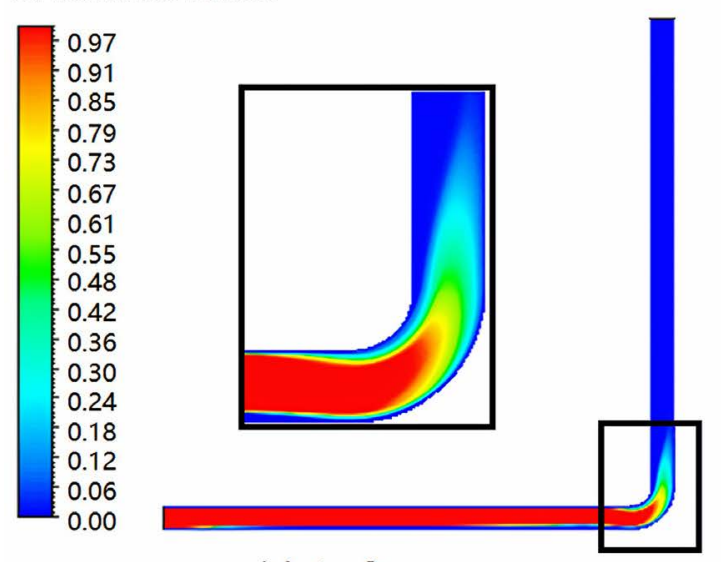

(a) $t=3 \mathrm{~s}$

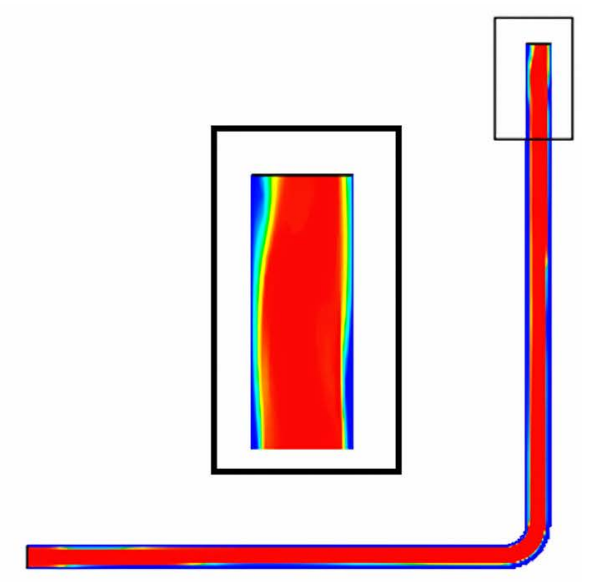

(b) $t=8 \mathrm{~s}$

Figure 5. Volumetric fraction field of oil along the pipe at different moments.

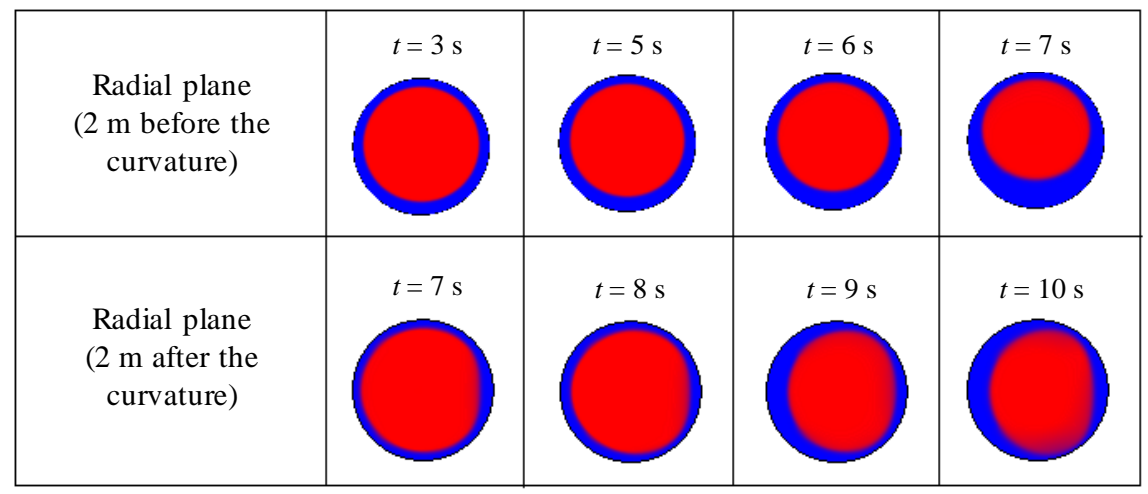

Figure 6. Volumetric fraction field of oil in transversal planes before and after the curvature point at different moments. 
mainly due to the difference in density between the two fluids, inducing interfacial waves in the core-annular flow and at the same time increasing, even more, its hydrodynamic stability. This behavior can be seen clearly in Figure 6, especially of the times equal to 7,9 , and $10 \mathrm{~s}$.

Regarding the oil velocity behavior illustrated in Figure 7 and Figure 8, it is observed clearly the presence of a water stream near the pipe wall. From the analysis of the predicted results, the superficial velocity of heavy oil tends to be zero as the radius, $r$, increases approaching the radius of the pipe, $R$, evidence

Oil superficial velocity

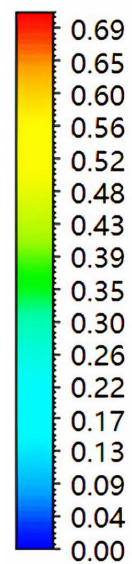

$\left[\mathrm{m} \mathrm{s}^{\wedge}-1\right]$
Oil superficial velocity

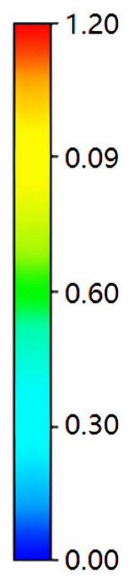

$\left[\mathrm{m} \mathrm{s}^{\wedge}-1\right]$

(a)

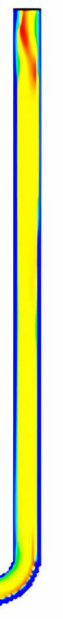

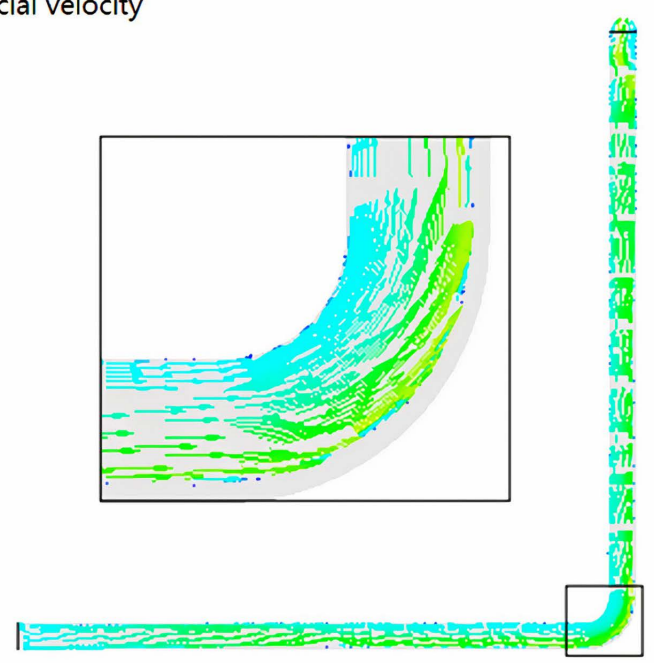

(b)

Figure 7. (a) Superficial velocity field and (b) velocity vectors of the heavy oil at $t=8 \mathrm{~s}$.

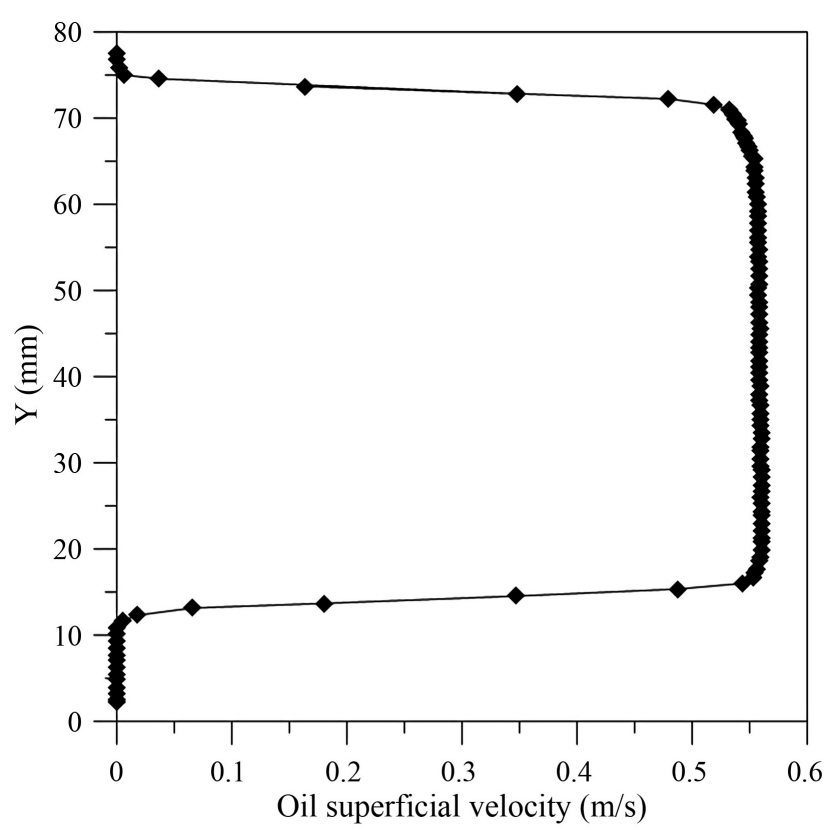

(a)

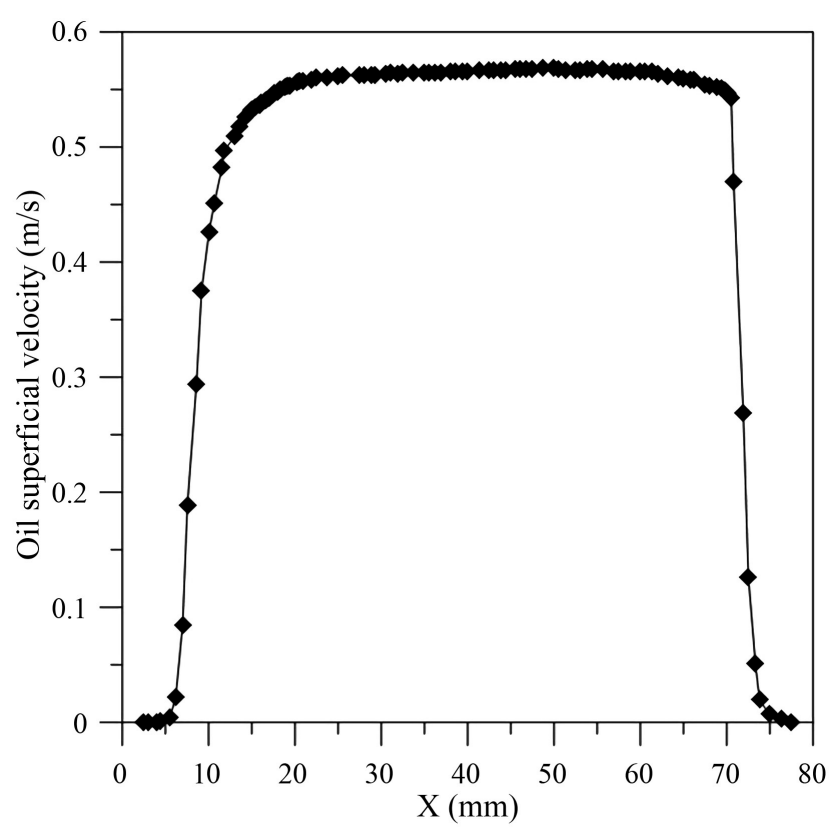

(b)

Figure 8. Oil superficial velocity profile at (a) $2 \mathrm{~m}$ before curvature and (b) at $2 \mathrm{~m}$ after curvature. 
that it does not touch the pipe wall, not even in the curvature region, confirming the oil core lubrication performed by the water flow, reaching a maximum superficial velocity of $0.56 \mathrm{~m} / \mathrm{s}$.

\section{Conclusions}

From the obtained results, it can be concluded that:

1) The core-flow technique proved to be an excellent alternative solution for the transport of heavy oils due to the reduction in the energy consumption used in the process;

2) The use of the core-flow technique for the proposed problem presented a reduction factor in the pressure drop of 28.4 compared to the heavy oil single-phase flow;

3) The use of the core-flow technique provided a maximum reduction in pressure drop equal to $\Delta P=2879.37 \mathrm{~Pa}$ and the maximum required power of $41.14 \mathrm{~W}$;

4) The reduction in pressure drop when using the core-flow technique was 96.48\%;

5) During the entire process, the oil core was stable and non-concentric, not even touching the pipe wall;

6) In pipeline projects for transporting heavy oils, the radius of curvature must be analyzed during the design process, to avoid breaking the stability of the core-flow pattern due to its high local pressure drop.

\section{Acknowledgements}

The authors thank CNPq, CAPES, FINEP, and ANP (Brazilian Research Agencies) for financial support.

\section{Conflicts of Interest}

The authors declare no conflicts of interest in this paper.

\section{References}

[1] França, A.F. (2006) New Technologies (and Challenges) in the Petroleum Production in Brazil. SBPC. http://www.sbpcnet.org.br/livro/58ra/atividades/TEXTOS/texto 890.html

[2] OECD (2005) Resources to Reserve: Oil and Gas Technologies for the Energy Markets of the Future. International Energy Agency, Paris.

[3] Mothé, C.G. and Silva, C. (2007) Heavy and Ultra-Heavy Oil-Reserves and World Production. TN Petroleum, 57, 76-81. (In Portuguese)

[4] Hart, A. (2013) A Review of Technologies for Transporting Heavy Crude Oil and Bitumen via Pipelines. Journal of Petroleum Exploration and Production Technology, 4, 327-336. https://doi.org/10.1007/s13202-013-0086-6

[5] Bannwart, A.C. (2001) Modeling Aspects of Oil-Water Core-Annular Flows. Journal of Petroleum Science and Engineering, 32, 127-143.

https://doi.org/10.1016/S0920-4105(01)00155-3 
[6] Charles, M.E., Govier, G.W. and Hodson, G.W. (1961) The Horizontal Pipeline Flow of Equal Density Oil-Water Mixtures. The Canadian Journal of Chemical Engineering, 39, 27-36. https://doi.org/10.1002/cjce.5450390106

[7] Oliemans, R.V.A., Ooms, G., Wu, H.L. and Duijvestijn. A. (1987) Core-Annular Oil/Water Flow: The Turbulent-Lubricating-Film Model and Measurements in a 5 cm Pipe Loop. International Journal Multiphase Flow, 13, 23-31. https://doi.org/10.1016/0301-9322(87)90004-8

[8] Arney, M.S., Bai, R., Guevara, E., Joseph, D.D. and Liu, K. (1993) Friction Factor and Holdup Studies for Lubricated Pipelining-I. Experiments and Correlations. International Journal of Multiphase Flow, 19, 1061-1076. https://doi.org/10.1016/0301-9322(93)90078-9

[9] Joseph, D.D., Bai, R., Chen, K.P. and Renardy, Y.Y. (1997) Core-Annular Flows. Annual Reviews Fluid Mechanical, 29, 65-90.

https://doi.org/10.1146/annurev.fluid.29.1.65

[10] Bensakhria, A., Peysson, Y. and Antonini, G. (2004) Experimental Study of the Pipeline Lubrication for Heavy Oil Transport. Oil \& Gas Science and Technology, 59, 523-533. https://doi.org/10.2516/ogst:2004037

[11] Usha, R. and Sahu, K.C. (2019) Interfacial Instability in Pressure-Driven Core-Annular Pipe Flow of a Newtonian and a Herschel-Bulkley Fluid. Journal of Non-Newtonian Fluid Mechanics, 271, 104-114. https://doi.org/10.1016/j.jnnfm.2019.104144

[12] Sarmadi, P. and Frigaard, I.A. (2019) Stable Core-Annular Horizontal Flows in Inaccessible Domains via a Triple-Layer Configuration. Chemical Engineering Science: $X$, 3, 1-12. https://doi.org/10.1016/j.cesx.2019.100028

[13] Coelho, N.M.A., Taqueda, M.E.S., Souza, N.M.O., Paiva, J.L., Santos, A.R., Lia, L.R.B., Moraes, M.S. and Morais Junior, D. (2020) Energy Savings on Heavy Oil Transportation through Core Annular Flow Pattern: An Experimental Approach. International Journal of Multiphase Flow, 122, 103-127. https://doi.org/10.1016/j.ijmultiphaseflow.2019.103127

[14] Cavicchio, C.A.M., Biazussi, J.L., Castro, M.S., Bannwart, A.C, Rodriguez, O.M.H. and Carvalho, C.H.M. (2018) Experimental Study of Viscosity Effects on Heavy Crude Oil-Water Core-Annular Flow Pattern. Experimental Thermal and Fluid Science, 92, 270-285. https://doi.org/10.1016/j.expthermflusci.2017.11.027

[15] Dehkordi, P.B., Colombo, L.P.M., Mohammadian, E., Azdarpour, A. and Sotgia, G. (2019) The Influence of Abruptly Variable Cross-Section on Oil Core Eccentricity and Flow Characteristics during Viscous Oil-Water Horizontal Flow. Experimental Thermal and Fluid Science, 105, 261-277. https://doi.org/10.1016/j.expthermflusci.2019.03.026

[16] Cazarez-Candia, O. and Piedra-González, S. (2017) Modeling of Heavy Oil-Water Core-Annular Upward Flow in Vertical Pipes Using the Two-Fluid Model. Journal of Petroleum Science and Engineering, 150, 146-153.

https://doi.org/10.1016/j.petrol.2016.12.004

[17] Conceição, S.B., Lima, A.G.B., Andrade, T.H.F., Farias Neto, S.R., Oliveira, V.A.B., Angelim, K.C.L. and Rocha, L.A. (2017) Applying CFD in the Analysis of Heavy-Oil Transportation in Curved Pipes Using Core-Flow Technique. The International Journal of Multiphysics, 11, 169-186. http://dx.doi.org/10.21152/1750-9548.11.2.169

[18] Andrade, T.H.F., Farias Neto, S.R., Lima, A.G.B., Silva, C.J. and Lima, W.M.P.B. (2014) Operation Control of Fluids Pumping in Curved Pipes during Annular Flow: A Numerical Evaluation. The International Journal of Multiphysics, 8, 271-284. 
http://dx.doi.org/10.1260/1750-9548.8.3.271

[19] Andrade, T.H.F., Silva, F.N., Farias Neto, S.R. and Lima, A.G.B. (2013) Applying CFD in the Analysis of Heavy Oil-Waterer Two-Phase Flow in Joints by Using Core Annular Flow Technique. The International Journal of Multiphysics, 7, 137-152. http://dx.doi.org/10.1260/1750-9548.7.2.137

[20] Andrade, T.H.F., Crivelaro, K.C.O., Farias Neto, S.R. and Lima, A.G.B. (2013) Isothermal and Non-Isothermal Water and Oil Two-Phase Flow (Core-Flow) in Curved Pipes. The International Journal of Multiphysics, 7, 167-182. http://dx.doi.org/10.1260/1750-9548.7.3.167

[21] Farias Neto, S.R., Santos, J.S.S., Crivelaro, K.C.O., Farias, F.P.M. and Lima, A.G.B. (2012) Heavy Oils Transportation in Catenary Pipeline Riser: Modeling and Simulation. In: Ochsner, A., da Silva, L.F.M. and Altenbach, H., (Org.), Materials with Complex Behaviour II: Properties, Non-Classical Materials, and New Technologies. Series. Advanced Structured Materials, Volume 16 Springer-Verlag, Heidelberg, 229-250. https://doi.org/10.1007/978-3-642-22700-4_ 13

[22] Ameri, M. and Tirandaz, N. (2017) Two Phase Flow in a Wavy Core-Annular Configuration through a Vertical Pipe: Analytical Model for Pressure Drop in Upward Flow. International Journal of Mechanical Sciences, 126, 151-160.

https://doi.org/10.1016/j.ijmecsci.2017.03.034

[23] Strazza, D. and Poesio, P. (2012) Experimental Study on the Restart of Core-Annular Flow. Chemical Engineering Research and Design, 90, 1711-1718. https://doi.org/10.1016/j.cherd.2012.03.011

[24] ANSYS Inc. (2019) CFX-Theory Manual Guide. 